\title{
Digitalization of Work Systems—An Organizational Routines' Perspective
}

\author{
Verena Wolf \\ Paderborn University \\ verena.wolf@upb.de
}

\author{
Christian Bartelheimer \\ Paderborn University \\ christian.bartelheimer@upb.de
}

\author{
Daniel Beverungen \\ Paderborn University \\ daniel.beverungen@upb.de
}

\begin{abstract}
Digitalization is a hypernym that denotes the ground-shifting impact IT artifacts have on organizations. The term implicitly refers to core topics in Information Systems research, which now enfolds at increasing magnitude, speed, and reach. However, digitalization often lacks explicit references to domestic theories, concepts, and constructs in the Information Systems literature. Fundamental mechanisms that constitute digitalization as an interplay of organizations and information systems remain unexplored. The purpose of this paper is twofold. First, based on extending extant theory on organizational routines, we propose four patterns that conceptualize digitalization mechanisms as an interplay of organizational routines and IT artifacts. Second, we demonstrate how more complex transformation trajectories of routines unfold, by concatenating our patterns to form transformation stories. On either level of abstraction, further research can build on the proposed patterns to theorize on how the interplay of IT artifacts and organizational routines constitutes the digitalization of work systems.
\end{abstract}

\section{Introduction}

The accelerating design and diffusion of new (digital) technologies reshape all elements within and around organizations [15, 31]. Despite the wide recognition and potential of digital technologies, most organizations are still struggling with digitally transforming their organization [65]. On top of that, digitalization is still a hyped concept that lacks reference to the constructs that constitute the Information Systems (IS) discipline. In general, digitalization refers to "[...] changes that are associated with the application of digital technology" [40]. Digitalization is not a completely new phenomenon since it is related to the concept of IT-induced change. Related research has mostly focused on substantial changes and underestimates the significance of the micro-dynamics that constitute a change process [71].
To connect digitalization with the properties of organizations, we use the work system framework (WSF) [1]. We position our research at the center of the WSF, i.e., processes and activities, as a suitable lens to discover micro-dynamics of digitalization in organizations. Thereby, we focus on how digitalized processes and activities are carried out to provide innovative products and services, and how processes and activities in an organization are orchestrated by participants, information, and technology [50].

To examine digitalization in processes and activities, we draw on the established theory of organizational routines [13, 62], which, in turn, is rooted in structuration theory [34]. Organizational routines, in the following simply referred to as routines, are key for understanding how organizations accomplish their tasks, how they change [29], and how capabilities are accumulated, transferred, and applied [18]. As a construct, a routine comprises two mutually constitutive dimensions, namely ostensive aspects (i.e., abstract structures of a routine) and performative aspects (i.e., enactments of a routine). Apart from this interplay, both aspects are influenced by technology, and vice versa, they influence technology [62]. In particular, IT artifacts enable and constrain the ostensive and performative aspects of routines [13]. The imbrication of human and material agency can create new routines and induce changes of IT artifacts that employees utilize for performing work activities [53]. In IS literature, artifacts and routines have been conceptualized through a micro-dynamic lens with artifact either at the periphery $[13,62]$ or center of routines, balancing each other out [24]. However, the routines' perspective has not been used to systematize digitalization as an endogenously changing pattern that occurs in work systems.

To fill the gap between the importance of digitalization for organizations and the available body of knowledge on the micro-dynamics of IT-induced change in IS research, we strive to answer the following research question: How does the digitalization of organizations unfold, when viewed from the micro-dynamic perspective of endogenously changing routines? In this regard, the paper offers two important contributions. First, we use qualitative data 
to conceptualize four patterns of how the ostensive and performative aspects of routines interplay with IT artifacts. Second, we illustrate how the patterns can be concatenated to describe more complex transformation trajectories in digital work systems. Subsequent research can use our patterns to empirically identify and analyze mechanisms of process digitalization, from isolated events to longitudinal transformation paths.

The paper unfolds as follows. In Section 2, we systematize current literature on digitalization by looking at the elements within a work system, pointing out that processes and activities in digitalized organizations are under-researched. Therefore, we reflect on routines as a theoretical lens to investigate the interplay of activities/processes and information technology in an organization to enhance the current understanding on the micro-foundations of IT-induced change. In Section 3, we describe and justify our qualitative empirical research approach and analyze, code, and categorize the data to conceptualize four patterns that frame the micro-dynamic interplay of routines and IT artifacts. In Section 4, we illustrate how the identified patterns manifest in work systems and how they can be concatenated to form transformation stories. Section 5 concludes the paper.

\section{Related research}

\subsection{Digitalization of work systems}

The acceleration of technology innovation cycles and the integration of digital technologies into daily business affect every part of an organization [58]. Potential benefits are manifold, including process innovation, product innovation, and digital innovation [44]. Organizations have recognized these advantages. Hence, digital transformation is an emerging term that is part of many C-level executives' top priorities [78].

To understand digital transformation, it is necessary to know the concepts of digitalization and digitization. Both in literature and organizations, no common understanding of these terms exists [39]. Digital transformation, digitalization, and digitization are often used as synonyms [32], even if they differ conceptually.

Digital transformation is defined as "[...] a technology-induced change on many levels in the organization that includes both the exploitation of digital technologies to improve existing processes and the exploration of digital innovation" [11]. It is characterized as a disruptive or incremental change process that transforms an organization fundamentally for a new digital economy [41, 42]. Digital transformation is driven by economic trends (e.g., globalization and sharing economy), a demand for technology, and consumer trends [72]. Evidence shows that $84 \%$ of organizations struggle [69] with developing visions, plans, and implementations for transforming digitally because they regard digital transformation as a prerogative of the IT department [32] and not as an organizational task [69].

We propose that digital transformation is implemented through the digitization and digitalization of work systems - a concept argued to be "a natural unit of analysis for thinking about systems in organizations" [2]. Digitization describes the conversion of analogue source material into a digital format, and into binary digits $[42,76]$. Digitalization refers to a socio-technical process of applying digitization techniques to a broader social and institutional context [76]. Hence, digital transformation is applied through emerging digital technologies [67] intertwined with digitization (i.e., turn analogue signals into digital variants) and digitalization (i.e., apply digitization techniques on an organizational level).

Digitalization has a fundamental impact on many aspects of an organization, including processes, resources, and internal and external parties [40]. An organization can be conceptualized as a socio-technical system consisting of multiple actors and/or machines that perform processes and activities, using information and technology to produce products and services [2]. Therefore, we take the WSF [1] as a theoretical lens to discuss extant literature and locate our research focus in an organization's structure. The WSF [1] "identifies nine elements that are part of $[\ldots]$ a work system: customers, products and services, processes and activities, participants, information, technologies, environment, infrastructure, and strategies" [3].

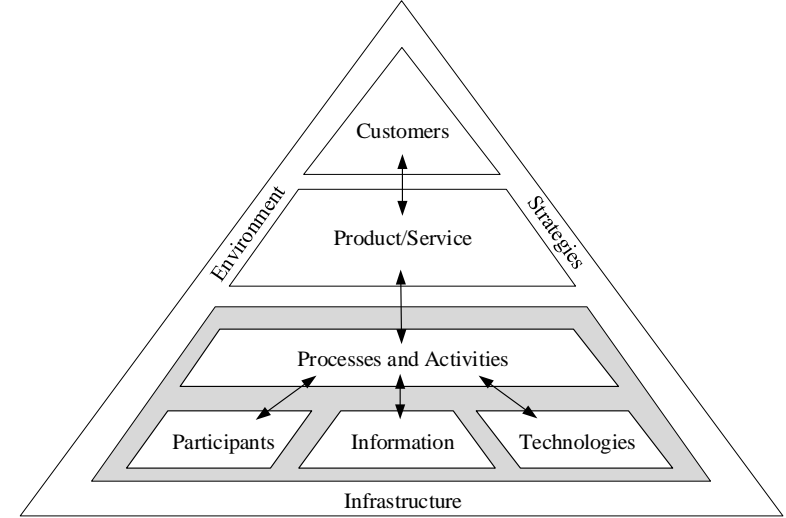

Figure 1. The work system framework [1]

Elements within a work system, i.e., participants, information, technologies, processes and activities, product/services, and customers, serve as concepts to address the changes that occur within organizations, triggered by emergent digital technologies. These 
concepts enable us to logically structure and discuss the internal transformation of organizations triggered by digitalization - closing the gap between what is known and what still needs to be discovered to explain digitally induced change in work systems.

In regard to the concept of digitalization, uncertainty and confusion are evident in many papers that use digitalization as a synonym for digital transformation [12, 32, 40, 47, 68]. Current research focuses on digitalization as a challenge for participants that use technology in their day-to-day work and to explain how work is redesigned in the digital era [12, 16, 27, 60, 70, 73, 77, 80]. Furthermore, many articles conceptualize information as digitized data $[5,17,33$, 37, 74], refer to technologies as an enabler of digitalization [14, 47, 48, 68], or focus on digitized value propositions of products/services [4, 19, 46, 59, 66] that are adapted to changing customer demand or customer feedback [26, 52, 65, 75].

In contrast, research seldom examines digitalization from the viewpoint of processes and activities in a work system $[6,43,51]$. Some authors investigate how organizations converted business activities into a digital format, e.g., through internet-enabled digitalization [6]. Others describe disruptive trends that impact how processes and activities are performed [51]. One article describes a specific case of how digitalization can restructure a manufacturing process to improve efficiency, responsiveness, and reduce costs [43]. Even though previous research provides important insights, it fails to identify the mechanisms that constitute transformation as a micro-dynamic interplay of processes/activities and IT artifacts.

Digital technologies have become an integral part of daily routines [65], impacting what work is done and the way how work is done [60]. Work within an organization can be described in business processes as a sequence of activities [13]. Subsequently, we focus on how processes and activities evolve through new IT artifacts, and vice versa. Focusing on processes and activities as core units of analysis is in line with the WSF, since processes and activities, participants, information, and technologies are the key components that constitute a work system [3].

\subsection{Organizational routines in work systems}

Processes in a work system can be described as patterns of activities. This concatenation of procedural activities - which is primed by and priming the actions of others - is manifested as a routine [18]. Processes constitute a subset of routines [8] and statically follow a given logic and structure. Routines incorporate both flexibility and stability and describe patterns of day-to- day work in a work system-including those tasks that are not orchestrated in a process.

Routines are often defined as repetitive and recognizable behavior that can be carried out collectively (multi-person) or individually (singleperson) [9]. Actors, other routines, or external cues can trigger routines [8]. Further, routines can denote a set of rules or standard operating procedures $[18,21,28$, $56,64]$. Both definitions do not give credit to rapidly changing organizations and innovations [8] but emphasize the properties of routines as (social) structures that increase stability and oppose organizational change. To equally highlight routines as social structures and as vehicles for change, we consider routines as "continuously emerging systems with internal structure and dynamics" [8]. Routines are not mindless actions, but rather are effortful accomplishments [63]. They can refer to formalized and standardized procedures - such as mass transaction processes - as well as to tacit competencies, like coordination schemes in teams [79].

Routines are performed by participants who are capable of learning from experience, making routines "generative systems that produce repetitive, recognizable patterns of interdependent action" [61]. Hence, routines are an important source for endogenous change in organizations [45]. On a microlevel perspective, routines comprise two aspects. First, routines consist of ostensive aspects, which are abstract patterns that represent an ideal or schematic form of a routine and guide desired and offset undesired performances. Participants use the ostensive aspects to guide, account for, and refer to specific performances of a routine [61]. Second, the performative aspects of a routine are specific enactments, carried out at a specific time and under specific conditions [13].

Ostensive and performative aspects are mutually constitutive since ostensive aspects are the social structure that enables and constrains human actions, while the performance of a routine produces and reproduces the ostensive aspects through recurrent enactments [30]. The similarity or dissimilarity of the ostensive aspect and the performance of a routine indicates a change [23]. Each iteration of a routine can differ from the previous one, leading to an endogenous change of the overall routines [22]. Actors can decide to deviate from ostensive structures consciously or unconsciously through human agency [53].

In IS literature, routines have been studied in relation to (IT) artifacts that are either at the periphery $[13,62]$ or the center of routines, balancing each other out [24]. IT artifacts, such as constructs, models, methods, and software instantiations [57], are distinct from a routine and have a recursive relationship to the ostensive and performative aspects of a routine [62]. 
An IT artifact has a material agency that influences the emergence and persistence of routines [24].

Imbrication of human and material agency can change both routines and IT artifacts [53]. Hence, the ostensive and performative aspects of a routine are enabled and constrained by IT artifacts [13]. Vice versa, IT artifacts are designed and shaped by routines that are influenced by the work system in which rules and norms of behavior apply.

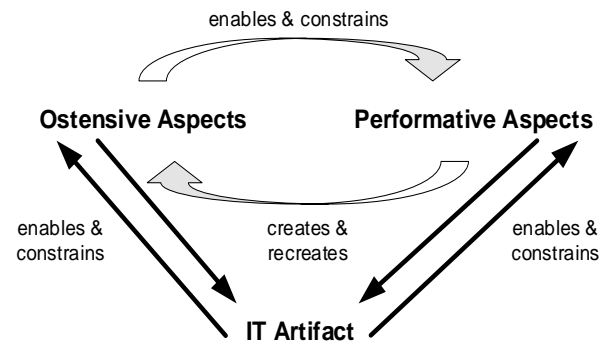

\section{Figure 2. Framework of routines and IT artifacts (adapted from $[13,62]$ )}

While the interplay of routines and IT artifacts has been discussed extensively, research needs to go beyond conceptualizing routines as a single pattern [63], to address the endogenously changing dynamics of digitalization that changes both, routines and IT artifacts. This view is in line with conceptualizing information systems as socio-technical systems that consist of technological components and organizational structure. These socio-technical systems are subject to ever fastening innovation cycles that create a constant demand for new IT artifacts and, therefore, the continuous adaption of routines.

Since routines are mutually constitutive systems that are enabled and constrained by cognitive, social, and physical structures, routines are a fundamental construct to identify drivers of change and their impact on organizations [10]. By taking a micro-dynamic routine's perspective, we extend the literature on the relationship of routines and IT artifacts as well as imbrication of human and material agency and conceptualize how digitalization of work systems unfolds.

\section{Research method}

\subsection{Research design}

To identify how IT artifacts affect routines and vice versa, we employed a qualitative empirical research approach and took the framework of routines and IT artifacts [13, 62] as a theoretical. Empirical research strategies are a valid methodology for gathering data on routines [79]. A qualitative research approach allows us to access the context in which individuals perform their day-to-day work in organizations.

Our sampling strategy is based on purposeful and maximal variation sampling by conducting semistructured interviews in different organizational settings. The interviews were conducted face-to-face and via telephone with 14 informants at different points in time over a period of ten months. To avoid biased data, the informants were chosen carefully, to represent different company sizes, regions, and industries-including automotive, machine tools, financial sectors, management consulting, accounting, IT, machinery/equipment supplier, and agriculture. Since routines within an organization can evolve over extended periods of time [79], we chose informants that had at least ten years of work experience in their organization or were responsible for steering transformation projects. Each interview took approximately 35 minutes, and we recorded 502 minutes of audio data. The informants reported on what routines constitute their work systems and how these routines transformed through digitalization.

We analyzed, coded, categorized, and examined the data we obtained from the transcribed interviews and additional field notes, by focusing on the content and meaning of statements. The data in the transcripts were coded independently by three researchers. Data were analyzed using an adapted grounded theory approach [35], in which we conducted three phases of analysis: open coding, axial coding, and selective coding [36]. The coding process was not linear but rather a recursive and analytical procedure [55].

First, we were sampling the statements that denote digitalization of work systems. Sampling was conducted in two phases starting with nine interviews that were the basis for a subsequent sampling phase, in which we conducted five additional interviews.

Through an initial open coding of the data [20], we identified broad themes, e.g., triggers of digitalization and changes within routine activities. The aggregated categories paved the way for the second phase of axial coding [20], in which we identified similarities and differences among the categories. Through selective coding, we linked the emergent themes to theoretical concepts that were identified in literature, describing mechanisms and trajectories of digitalizing routines.

Since we use an adapted approach of grounded theory, we deviated from the original procedure of iterative cycles in theoretical sampling. After the second phase of sampling and analyzing, we already discovered theoretical saturation since the data matched with initial categories and did not reveal any additional categories or sub-categories that would advance our theoretical understanding of digitalization. Therefore, we completed the sampling process at the 
"point of redundancy" [54], which we reached in our study after completing two phases. We used peer debriefings to avoid incorrectly or misinterpreted data and ensure validity [20]. We discussed the patterns we identified with impartial researchers, who were not involved in this study before.

To develop a conceptual framework that links, aggregates, and abstracts the theoretical concepts we identified, we refer to a framework of endogenously changing routines to explain and discuss digitalization patterns that can be used to explore transformation trajectories in organizations. Each areas of the resulting framework that illustrated the triggers of digitalization in work systems encompasses a different pattern that can be represented by a specific manifestation of the framework of transformational routines.

\subsection{Data analysis}

In two sampling phases, we analyzed the data by using open coding, axial coding, and selective coding [36]. The emergent concepts from each sampling phase were compared and validated with concepts from the literature. The concepts from the first sampling phase served as guides for a more focused data analysis, which is presented henceforth.

In the first step of open coding, we analyzed and aggregated critical events in the transformation stories reported by the informants, to identify recurring statements and categories. We compared recurring statements, aggregated them, and grouped them into categories, each illustrated by two to five aggregated statements (1st order categories in Figure 3). The 1st order categories refer to different triggers for a digitalization of work systems. The data show that individuals participating in a work system are one crucial enabler for digitalization - regarding their capabilities and the design of (digital) workarounds. Changing customer expectations are another driver for digitalization. Also, the informants stated that the availability of digital technologies on the market and the institutionalized transformation of an organization by management were crucial starting points for the digitalization of their work systems. After identifying 1 st order categories, we applied axial coding to identify any relationships among the categories to form more abstract 2nd order themes.

We discussed the themes iteratively until they were conceptually clear and disjoint. At this point, we recognized a strong need to group the themes, since some of them were based on the same fundamental principles. We identified the first group of themes as the digitalization of a work system by individuals (in particular, participants, and customers). A second theme emerged to describe digitalization as planned redesign of a work system by management. A third theme referred to the adoption and use of digital technology (mostly hardware, e.g., mobile devices) by people in organizations. A fourth theme identified the appropriation of tools from outside the work system.

$$
1 \text { st order categories }
$$

2nd order themes

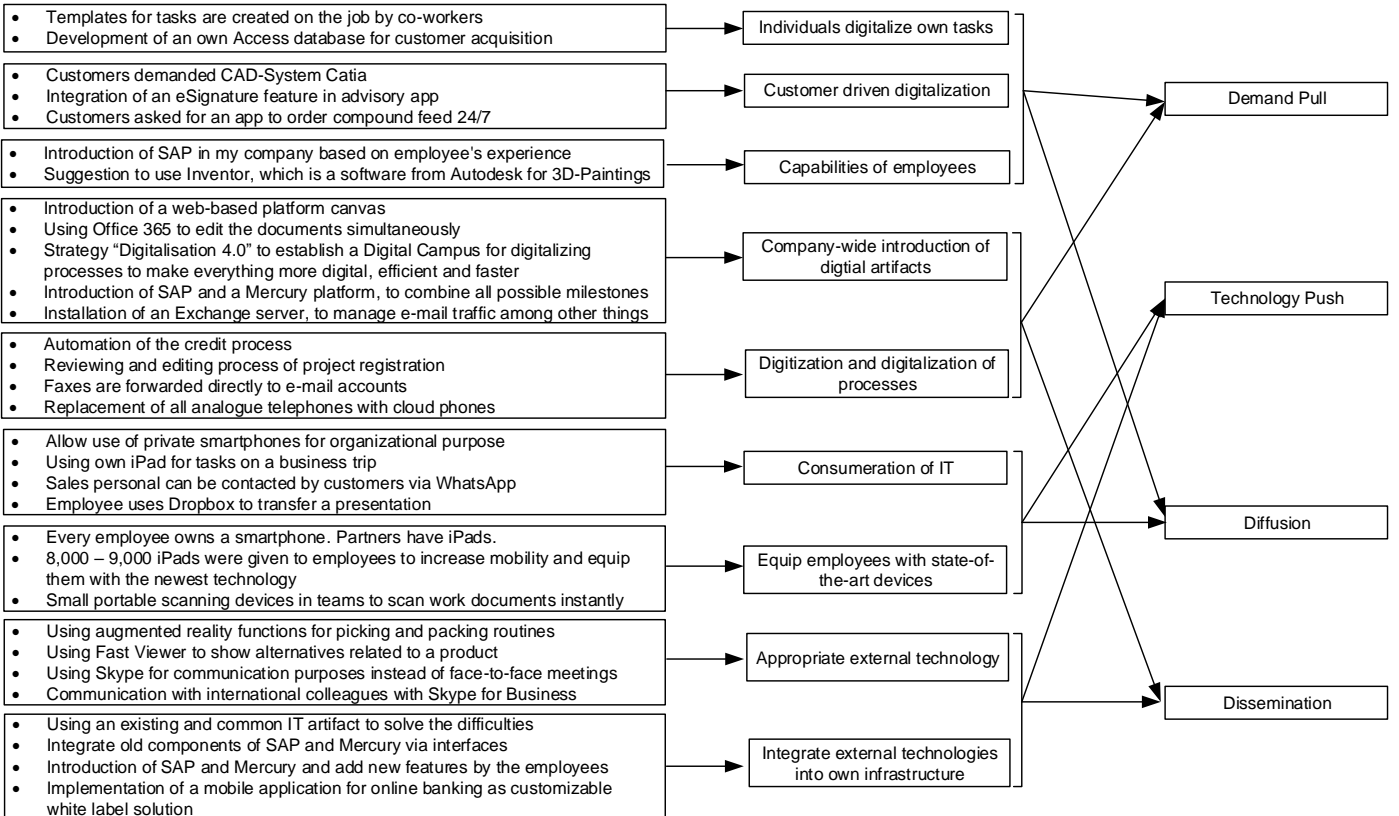

Figure 3. Identification of concepts [35] 
In the final phase of our data analysis, we searched for similarities between the 2nd order themes and matched them with theoretical concepts we identified in IS literature to form four 3rd order theoretical concepts. On the one hand, our data were mapped with constructs from IT-induced change, which describe that technological change is either triggered by demand pull or technology push. Demand pull is induced by individuals who formulate the need for an IT artifact, whereas technology push describes that an IT artifact is a driving factor for change $[7,51]$. On the other hand, we found comparable concepts to our data in the innovation literature. The spread of innovation in organizations was often described by informants with reference to the two concepts of diffusion and dissemination [25, 38]. Diffusion is the untargeted and unplanned spread of new practices (sometimes also referred as a bottom-up change process), whereas dissemination is the active spread of new practices using a planned strategy (sometimes also referred as a top-down change process).

\section{Digitalization of work systems}

\subsection{Interplay of organizational routines and IT artifacts, as mechanisms of digitalization}

Four patterns of digitalized routines emerged from our data. The patterns show that processes and activities-represented as routines-are the core of digitalization in work systems since they connect all elements in a work system.

Extending theory on routines [13, 62], our patterns illustrate how routines and IT artifacts interplay as mechanisms that constitute the digitalization of work systems from a micro-dynamic perspective (Figure 4). The framework identifies four directions between the ostensive/performative aspects and IT artifacts and adds two triggers for transforming routines (technology push, demand pull) as well as two forms of adopting IT artifacts for routines (dissemination, diffusion). The patterns are framed as follows:

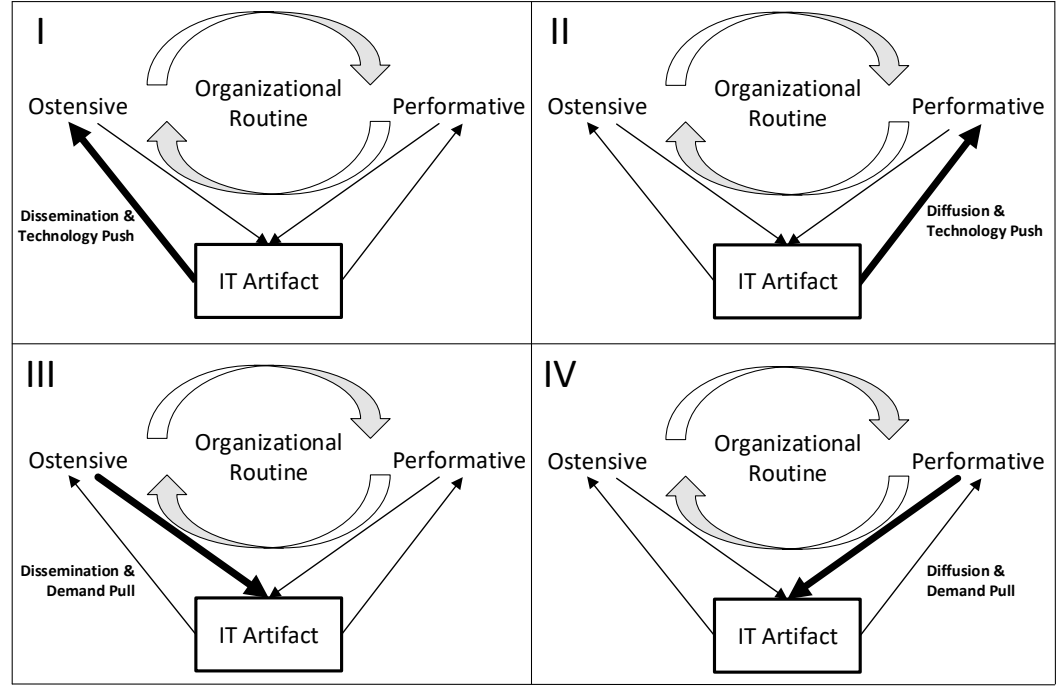

Figure 4. Extending patterns for digitalizing organizational routines in work systems $[13,62]$

Pattern I: An IT artifact is designed in the environment of a work system; it is then adopted by management to transform ostensive aspects of a routine inside a work system. IT artifacts like software (e.g., data analytics tools or mobile applications) or hardware (e.g., smartphones) that are available on the market are adopted by an organization through management: "Annual auditing is a routine process that complies with official auditing standards. Our management decided to introduce SAP and Mercury as a platform, to combine all possible milestones in auditing, e.g., order planning, acceptance, and processing to facilitate work of employees and merge all activities related to this process."

Pattern II: An IT artifact is designed in the environment of a work system; it is then adopted by employees to transform performative aspects of a routine inside a work system. IT artifacts designed in a work system's environment can be brought into an organization by employees. The artifacts then enable and constrain the performative aspects of a routine. Participants may include the IT artifact into their day-to-day work consciously or even unconsciously: "One year ago, we gave our employees 8,000 - 9,000 iPads to increase mobility 
and equip them with the newest technology. We have no guidelines using these iPads and provide our employees a lot of flexibility. They integrated these IT artifacts in their daily routine raising the need for the development of advisory applications that we have implemented subsequently. "

Pattern III: Work systems can transform ostensive aspects of a routine, leading to the design and implementation of IT artifacts that enable and constrain the transformed patterns. Transforming routines on an organizational level can lead organizations to design new IT artifacts. The altered ostensive aspects of a routine define the requirements that affect the desired form and function of new IT artifacts. This pattern illustrates that digitalization can be triggered by routines - as a concatenation of procedural actions - within a work system: "In the past, customers could only order compound feed online or through their local retail partners. However, customers demanded an app to order compound feed. Therefore, our salesforce redefined their standardized routine and initiated the development of an app to simplify order processes and boost availability to $24 / 7$ h service."

Pattern IV: Work systems can transform performative aspects of a routine, leading to the implementation of IT artifacts that enable and constrain the transformed performances. Participants that carry out a routine might alter the performative aspects of a routine themselves. The new routine may lead participants to request or implement an IT artifact that supports them in performing their day-to-day work. Whether a new IT artifact is designed or an existing one is brought into an organization depends on the accessibility of suitable and usable IT artifacts on the market. If an artifact is unavailable, a routine's specific enactment can trigger the development of a new IT artifact. The design of individual IT artifacts might be authorized, but it can also happen secretly, without authorization and beyond the control of management: "An employee used Dropbox to transfer a presentation (50 MB) to a third party since the organization's $e$ mail system could not send this large file. The security function flagged this as a critical breach of security policies. The existing IT infrastructure was not providing the needed functionality, and therefore, we created a secure solution to transfer large files."

\subsection{Longitudinal transformation trajectories}

In more complex digitalization projects, the patterns can be concatenated to document and analyze longitudinal transformation trajectories of activities or processes in a work system. This concatenation can be exemplified by data we collected on the digitalization of an annual audit.

The annual audit is a predefined routine task that needs to comply with official standards for auditing. The organization used a lot of proprietary software for distinct transactions and tasks that were unconnected. For the accountants, auditing was a cumbersome and time-consuming routine. Recently, the organization decided to introduce the existing IT artifacts SAP and Mercury (a platform for streamlining processes in SAP) to facilitate participants' auditing routine-including order planning, order acceptance, and order processingwith a neat platform. The platform was selected by management and transformed the ostensive aspects of a routine (dissemination \& technology push) inside a work system, which can be coded as Pattern I.

The informant further reports that the organization designed an interface to integrate previously used components and software programs with SAP. The integration was based on an organizational decision, and thereby, the trigger for the design of a new IT artifact again came from management. The interface represents a new IT artifact (demand pull) that was initiated by a change of the ostensive aspects of a routine, enabling participants to perform the routine as designed (dissemination) - representing Pattern III.

Participants of the work system were trained to use the software in their routine as specified in the ostensive aspects. Simultaneously, they already used the software in their day-to-day routines. Negative aspects and ideas for improvement were reported, leading to improvement and adaptation of the software. The employees reported those ideas from performing the auditing routine (diffusion). Functionalities of the software were adapted to participants' requirements, e.g., granting accessibility through a web-based service. These enhancements resulted in a new IT artifact (demand pull). Therefore, we code this effect as Pattern IV.

Employees of the auditing organization were accessing data through the web-based platform by using their smartphones to be more flexible in their day-to-day work. Thereby, they were changing the performative aspects of the routine (diffusion) without having been told to use their smartphones for this purpose (technology push). This transformation of the routine equals Pattern II.

The concatenation of these patterns illustrates how the audit routine was digitalized over time through the interplay of routines and IT artifacts in a work system. 


\section{Contribution and outlook}

Our paper offers two main contributions to research and management. First, we elucidate key properties of the digitalization of work systems and locate our research at the organization's center, which are processes and activities that can be described through routines. Although many papers seem to explore the attributes and triggers of digitalization, the term itself is used rather hazily as technologyinduced change. Seldom, research is focused on disruptive change, and no agenda is issued to research the detailed mechanisms related to transforming activities and processes in work systems. Our contribution is to connect digitalization to established concepts in the Information Systems discipline, to provide a strong set of constructs that others can use to perform empirical research on the digitalization of work systems.

Second, based on qualitative data, we identified four patterns that explain the mutually constitutive relationship of IT artifacts and routines. We showed that the patterns can be used for analyzing isolated effects that occur in the digitalization of work systems, while they can also be concatenated to code longitudinal transformation trajectories.

One limitation refers to the impact of digitalization on the outer elements of the WSF. Extending research by analyzing the effect on the ecosystem can help to understand digital transformation as a holistic concept. Considering the interplay of IT artifacts and routines, it remains unexplored what types of IT artifacts (including constructs, models, methods, and instantiations) [57] have sufficient potential to change routines. It seems conceivable that only instantiations, i.e., implemented software and hardware, exhibit this potential. Another limitation refers to the number of interviews we conducted. In qualitative research, data collection usually stops when saturation is reached. While we conducted interviews in two phases until the interviewees reported no new aspects, additional insights could have emerged from conducting interviews in different organizations.

Subsequent research can use our patterns to empirically investigate transformation projects in detail, describing trajectories of routines based on the interplay of IT artifacts and the routines' ostensive and performative aspects. Furthermore, clusters of routines, which form around technological complementarities might be identified [49]. Additional studies might also extend the proposed patterns or even identify additional patterns required to describe (digital) transformation stories. These results might enable us to identify why some routines are more or less generative in the vicinity of digitalization, depending on the way they are related. Unintended consequences, drift, and reach of digitalization [81], as effects that refer to the system's properties of organizations are particularly interesting and challenging fields of research that can benefit from applying the results offered by this paper.

\section{References}

[1] Alter, S., "The Work System Method for Understanding Information Systems and Information System Research", Communications of the Association for Information Systems, 9(1), 2002, pp. 90-104.

[2] Alter, S., ed., The Work System Method: Systems Thinking for Business Professionals, 2012.

[3] Alter, S., "Work System Theory: Overview of Core Concepts, Extensions, and Challenges for the Future", Journal of the Association for Information Systems, 14(2), 2013, pp. 72-121.

[4] Ardolino, M., M. Rapaccini, N. Saccani, P. Gaiardelli, G. Crespi, and C. Ruggeri, "The Role of Digital Technologies for the Service Transformation of Industrial Companies", International Journal of Production Research, 2017, pp. 1-17.

[5] Ashwell, M.L., "The Digital Transformation of Intelligence Analysis", Journal of Financial Crime, 24(3), 2017. [6] BarNir, A., J.M. Gallaugher, and P. Auger, "Business Process Digitization, Strategy, and the Impact of Firm Age and Size: The Case of the Magazine Publishing Industry", Journal of Business Venturing, 18(6), 2003, pp. 789-814. [7] Barras, R., "New Technology and the New Services: Towards an Innovation Strategy for Europe", Futures, 18(6), 1986, pp. 748-772.

[8] Becker, M.C., "Organizational Routines: A Review of the Literature", Industrial and Corporate Change, 13(4), 2004, pp. 643-678.

[9] Becker, M.C., "Applying Organizational Routines in Understanding Organizational Change", Industrial and Corporate Change, 14(5), 2005, pp. 775-791.

[10] Becker, M.C., N. Lazaric, R.R. Nelson, and S.G. Winter, "Applying Organizational Routines in Understanding Organizational Change", Industrial and Corporate Change, 14(5), 2005, pp. 775-791.

[11] Berghaus, S. and A. Back, eds., Stages in Digital Business Transformation: Results of an Empirical Maturity Study, 2016.

[12] Betchoo, N.K., "Digital Transformation and its Impact on Human Resource Management: A Case Analysis of Two Unrelated Businesses in the Mauritian Public Service", in Emerging Technologies and Innovative Business Practices for the Transformation of Societies, IEEE, 2016.

[13] Beverungen, D., "Exploring the Interplay of the Design and Emergence of Business Processes as Organizational Routines", Business \& Information Systems Engineering, 6(4), 2014, pp. 191-202.

[14] Bley, K., C. Leyh, and T. Schäffer, "Digitization of German Enterprises in the Production Sector - Do they know how "Digitized" they are?", Twenty-second Conference on Information Systems, San Diego, 2016. 
[15] Brynjolfsson, E. and A. McAfee, The Second Machine Age: Work, Progress, and Prosperity in a Time of Brilliant Technologies, W.W. Norton \& Company, New York, 2014. [16] Cascio, W.F. and R. Montealegre, "How Technology is Changing Work and Organizations", Annual Review of Organizational Psychology and Organizational Behavior, 3, 2016, pp. 349-375.

[17] Clemons, E.K., R.M. Dewan, R.J. Kauffman, and T.A. Weber, "Understanding the Information-Based Trans-

formation of Strategy and Society", Journal of Management Information Systems, 34(2), 2017, pp. 425-456.

[18] Cohen, M.D., "Individual Learning and Organisational Routine: Emerging Connections", Organisation Science, 2(1), 1991, pp. 135-139.

[19] Coreynen, W., P. Matthyssens, and W. van Bockhaven, "Boosting Servitization through Digitization: Pathways and Dynamic Resource Configurations for Manufacturers", Industrial Marketing Management, 60, 2017, pp. 42-53.

[20] Corley, K.G. and D.A. Gioia, "Identity Ambiguity and Change in the Wake of a Corporate Spin-Off", Administrative Science Quarterly, 49(2), 2004, pp. 173-208. [21] Cyert, R.M. and J.G. March, "A Behavioural Theory of the Firm”, Oxford, Blackwell, 1963.

[22] Danner-Schröder, A., and D. Geiger, "Unravelling the Motor of Patterning Work: Toward an Understanding of the Microlevel Dynamics of Standardization and Flexibility", Organization Science, 27(3), 2016, pp. 633-658.

[23] D'Adderio, L., "The Replication Dilemma Unravelled: How Organizations Enact Multiple Goals in Routine Transfer", Organization Science, 25(5), 2014, pp. 1325-1350. [24] D'Adderio, L., "Artifacts at the Centre of Routines: Performing the Material Turn in Routines Theory", Journal of Institutional Economics 7(2), 2011, pp. 197-230.

[25] Dearing, J.W., "Evolution of Diffusion and Dissemination Theory", Journal of Public Health Management and Practice, 14(2), 2008, pp. 99-108.

[26] Dellarocas, C., "The Digitization of Word of Mouth: Promise and Challenges of Online Feedback Mechanisms", Management science, 49(10), 2003, pp. 1407-1424.

[27] Dery, K., I.M. Sebastian, and N. van der Meulen, "The Digital Workplace is Key to Digital Innovation", MIS Quarterly Executive, 16(2), 2017.

[28] Egidi, M., "Routines Hierarchies of Problems, Procedural Behaviour: some Evidence from Experiments, Macmillan", London, 1996.

[29] Feldman, M. S., "Organizational Routines as a Source of Continuous Change", Organization Science 11(6), 2000, pp. 611-629.

[30] Feldman, M.S. and B.T. Pentland, "Reconceptualizing Organizational Routines as a Source of Flexibility and Change", Administrative Science Quarterly, 48(1), 2003, pp. 94-118.

[31] Fichman, R.G., B.L. Dos Santos, and Z.E. Zheng, "Digital Innovation as a Fundamental and Powerful Concept in the Information Systems Curriculum", MIS Quarterly, 38(2), 2014.

[32] Ganguly, A., "Optimization of IT and Digital Transformation: Strategic Imperative for Creating a New Value Delivery Mechanism and Sustainable Future in Organization", European Journal of Business and
Innovation Research, 3(2), 2015, pp. 1-13. [33] Gasova, K. and K. Stofkova, "E-Government as a Quality Improvement Tool for Citizens' Services”, Procedia engineering, 192, 2017, pp. 225-230. [34] Giddens, A., "Structuration Theory, Empirical Research and Social Critique", A. Giddens, The constitution of society: Outline of the theory of structuration, 1984, pp. 281-305.

[35] Gioia, D.A., J.B. Thomas, S.M. Clark, and K. Chittipeddi, "Symbolism and Strategic Change in Academia: The Dynamics of Sensemaking and Influence", Organization Science, 5(3), 1994, pp. 363-383. [36] Glaser, B.G. and A.L. Strauss, The Discovery of Grounded Theory: Strategies for Qualitative Research, $4^{\text {th }}$ edn., Aldine, New Brunswick, 2009.

[37] Gölzer, P. and A. Fritzsche, "Data-Driven Operations Management: Organisational Implications of the Digital Transformation in Industrial Practice", Production Planning \& Control, 28(16), 2017, pp. 1332-1343.

[38] Greenhalgh, T., G. Robert, F. Macfarlane, P. Bate, and O. Kyriakidou, "Diffusion of Innovations in Service Organizations: Systematic Review and Recommendations", The Milbank Quarterly, 82(4), 2004, pp. 581-629.

[39] Hanelt, A., E. Piccinini, R.W. Gregory, B. Hildebrandt, and L. Kolbe, "Digital Transformation of Primarily Physical Industries - Exploring the Impact of Digital Trends on Business Models of Automobile Manufactures", International Conference on Wirtschaftsinformatik, 12, 2015, pp. 1313-1327. [40] Henriette, E., M. Feki, and I. Boughzala, "The Shape of Digital Transformation: A Systematic Literature Review", MCIS 2015 Proceedings, (9), 2015, pp. 1-13. [41] Henriette, E., M. Feki, and I. Boughzala, "Digital Transformation Challenges", Mediterranean Conference on Information Systems Proceedings, 10, 2016, pp. 1-7. [42] Hess, T., C. Matt, A. Benlian, and F. Wiesböck, "Options for Formulating a Digital Transformation Strategy”, MIS Quaterly, 15(2), 2016, pp. 123-139. [43] Holmström, J. and J. Partanen, "Digital ManufacturingDriven Transformations of Service Supply Chains for Complex Products", Supply Chain Management: An International Journal, 19(4), 2014, pp. 421-430.

[44] Horlacher, A., "Co-Creating Value-the Dyadic CDOCIO Relationship during the Digital Transformation", European Conference on Information Systems Proceedings, 24, 2016, pp. 1-11.

[45] Howard-Grenville, J. A, "The Persistence of Flexible Organizational Routines: The Role of Agency and Organizational Context", Organization science 16(6), 2005, pp. 618-636.

[46] Javaid, A., S. Kurjakovic, H. Masuda, and Y. Kohda, "Enabling Digital Transformation in SMEs by Combining Enterprise Ontologies and Service Blueprinting", International Conference ICServ Proceedings, 5, 2017, pp. 224-233.

[47] Klötzer, C., J. Weißenborn, and A. Pflaum, "The Evolution of Cyber-Physical Systems as a Driving Force Behind Digital Transformation", Conference on Business Informatics, 19, 2017, pp. 5-14.

[48] Korhonen, J.J. and M. Halén, "Enterprise Architecture for Digital Transformation", IEEE Conference on Business 
Informatics, 19, 2017, pp. 349-358.

[49] Kremser, W. and G. Schreyögg, "The Dynamics of Interrelated Routines: Introducing the Cluster Level", Organization Science, 27(3), 2016, pp. 698-721.

[50] Laumer, S., C. Maier, A. Eckhardt, and T. Weitzel, "Work Routines as an Object of Resistance During Information Systems Implementations: Theoretical Foundation and Empirical Evidence", European Journal of Information Systems, 25, 2016, pp. 317-343.

[51] Lederer, M., J. Knapp, and P. Schott, "The Digital Future Has Many Names-How Business Process Management Drives the Digital Transformation”, International Conference on Industrial Technology and Management, 6, 2017, pp. 22-26.

[52] Leipzig, T., M. Gamp, D. Manz, K. Schöttle, P. Ohlhausen, G. Oosthuizen, D. Palm, and K. von Leipzig, "Initialising Customer-Orientated Digital Transformation in Enterprises", Procedia Manufacturing 8, 2017, pp. 517-524. [53] Leonardi, P M., "When Flexible Routines Meet Flexible Technologies: Affordance, Constraint, and the Imbrication of Human and Material Agencies", MIS Quarterly, 35(1), 2011, pp. 147-167.

[54] Lincoln, Y. S., and E. G. Guba, "Naturalistic Inquiry" (Vol. 75), Sage, 1985.

[55] Locke, K., "Rewriting the Discovery of Grounded Theory after 25 Years?", Journal of Management Inquiry, 5(3), 1996, pp. 239-245.

[56] March, J.G. and H.A. Simon, “Organizations”, Wiley, Oxford, England, 1958.

[57] March, S.T. and G.F. Smith, "Design and Natural Science Research on Information Technology", Decision Support Systems, 15(4), 1995, pp. 251-266.

[58] Matt, C., T. Hess, and A. Benlian, "Digital

Transformation Strategies", Business \& Information Systems Engineering, 57(5), 2015, pp. 339-343.

[59] Mocker, M. and N.O. Fonstad, "Driving Digitization at Audi", International Conference on Information Systems, 38, 2017, pp. 1-15.

[60] Müller, B. and U. Renken, "Helping Employees to be Digital Transformers - The Olympus.connect Case", International Conference on Information Systems, 38, 2017, pp. 1-19.

[61] Pentland, B.T. and M.S. Feldman, "Designing

Routines: On the Folly of Designing Artifacts, While

Hoping for Patterns of Action", Information and

Organization, 18(4), 2008, pp. 235-250.

[62] Pentland, B.T. and M.S. Feldman, "Organizational

Routines as a Unit of Analysis", Industrial and Corporate Change, 14(5), 2005, pp. 793-815.

[63] Pentland, B.T. and H.H. Rueter, "Organizational

Routines as Grammars of Action", Administrative Science Quaterly, 39(3), 1994, pp. 484-510.

[64] Pentland, B.T., Singh, H., and E. Yakura, "Routinizing Change: Does Business Process Management Technology

Have Unintended Firm-Level Consequences?”, Social and Organizational Impacts of IS, Thirty Third International Conference on Information Systems, Orlando, 2012.

[65] Piccinini, E., A. Hanelt, R. Gregory, and L. Kolbe,

"Transforming Industrial Business: The Impact of Digital

Transformation on Automotive Organizations",

International Conference on Information Systems, 36,
2015, pp. 1-20.

[66] Porter, M.E. and J.E. Heppelmann, "How Smart, Connected Products Are Transforming Companies", Harvard Business Review, 93(10), 2015, pp. 96-114. [67] Priyadarshy, S., "Digital Transformation Essential for E\&P Industry to Thrive in New Economy", World Oil, 2017, pp. 66-67.

[68] Roedder, N., D. Dauer, K. Laubis, P. Karaenke, and C. Weinhardt, "The Digital Transformation and Smart Data Analytics: An Overview of Enabling Developments and Application Areas", IEEE International Conference on Big Data, 2016, pp. 2795-2802.

[69] Rogers, B., "Why $84 \%$ of Companies Fail at Digital Transformation", 2016, Available at: https://www.forbes.com/sites/brucerogers/2016/01/07/ why-84-of-companies-fail-at-digital-transformation/, accessed 11-13-2017.

[70] Schuchmann, D. and S. Seufert, "Corporate Learning in Times of Digital Transformation: A Conceptual Framework and Service Portfolio for the Learning Function in Banking Organisations", International Journal of Advanced Corporate Learning (iJAC), 8(1), 2015, p. 31. [71] Schwarz, G. M., and A. D. Shulman, "The Patterning of Limited Structural Change", Journal of Organizational Change Management 20(6 ), 2007, pp. 829-846.

[72] Seeger, G. and M. Bick, "Mega and Consumer Trends Towards Car-independent Mobile Applications", International Conference on Mobile Business, 2013, Paper 27.

[73] Serrano, C. and M.-C. Boudreau, "When Technology Changes the Physical Workplace: The Creation of a New Workplace Identity", International Conference on Information Systems, 35, 2014, pp. 1-10.

[74] Seufert, S. and C. Meier, "From eLearning to Digital Transformation: a Framework and Implications for L\&D”, International Journal of Corporate Learning (iJAC), 9(2), 2016, pp. 27-33.

[75] Singh, A., B. Kumar, and V.K. Singh, "Customer engagement: New key metric of marketing", International Journal of Arts and Sciences, 3(13), 2010, pp. 347-356.

[76] Tilson, D., K. Lyytinen, and C. Sørensen, "Research Commentary-Digital Infrastructures: The Missing IS Research Agenda", Information systems research, 21(4), 2010, pp. 748-759.

[77] Timonen, H. and J. Vuori, "Visibility of Work: How Digitalization Changes the Workplace", in Proceedings of the $51^{\text {st }}$ Hawaii International Conference on System

Sciences. 2018.

[78] Verdino, G., "What is Digital Transformation, Really", 2015. Available at: http://www.gregverdino.com/digitaltransformation-definition/, accessed 7-4-2017.

[79] Warglien, M., "Hierarchical Selection and Organizational Adaption”, Industrial and Corporate Change, 4(1), 1995, pp. 161-186.

[80] Weber, B., J. Butschan, and S. Heidenreich, "Tackling Hurdles to Digital Transformation-the Role of Competencies for Successful IoT Implementation", IEEE Technology \& Engineering Management Conference (TEMSCON), 2017, pp. 312-317.

[81] Yi, S., Knudsen T. and T. Becker, "Inertia in Routines: A hidden source of organizational variation", Organization Science, 27(3), 2016, pp. 782-800. 